\title{
Field-scale performance of microelectrolysis-Fenton oxidation process combined with biological degradation and coagulative precipitation for landfill leachate treatment
}

\author{
Yuan-Yuan Zhao a,b, You-Ze Xu ${ }^{\mathrm{a}}$, Shuang Zhou ${ }^{\mathrm{a}}$, Jiao-Mei Liu ${ }^{\text {b* }}$, Yingxiang-Cheng ${ }^{\mathrm{a}}$, Guang-Yi Fu ${ }^{\mathrm{a}}$, Xiao-Song He \\ a Key Laboratory of Water Pollution Control Technology, Hunan Province, Hunan Research Academy of Environmental Sciences, \\ Changsha 410004, China State \\ ${ }^{\mathrm{b}}$ Chinese Research Academy of Environmental Sciences, Beijing 100012, China \\ ${ }^{\mathrm{c}}$ China Railway Fifth Survey And Design Institute Group CO.,LTD, Beijing China Railway Ecology \& Environment Densign Institute \\ CO.,LTD, Beijing 102600, China
}

\begin{abstract}
In order to verify the feasibility of $\mathrm{Fe} / \mathrm{C}$ microelectrolysis-Fenton oxidation for mature landfill leachate treatment in industrial application, this study conducted the treatment processes at full-scale by physicochemical and spectral characterization. The full-scale studies showed that $48.17 \%$ of the dissolved organic carbon (DOC) and $42.27 \%$ of the dissolved organic nitrogen (DON) were removed by the microelectrolysis-Fenton oxidation process, respectively. Spectra analysis further suggested that the mature leachate was mainly composed of tryptophan-like and fulvic-like compounds. The combination of microelectrolysis and Fenton oxidation efficiently decomposed the aromatic $\mathrm{C}=\mathrm{C}$ into carboxyl- $\mathrm{C}$ and decreased the molecular size of DOC, resulting in a dramatic reduce (97.1\%-98.3\%) of the fluorescence intensity. The DON removal by microelectrolysis-Fenton oxidation likely associated with the $\mathrm{NH}_{2}-$ decomposition of tryptophan-like and aromatic compounds into $\mathrm{NO}_{3}-\mathrm{N}$. The tryptophan-like compounds may play a dominant role in $\mathrm{Ba}$ binding, while $\mathrm{Pb}$ and $\mathrm{Cd}$ were likely bound to both the tryptophan-like and fulvic-like compounds. Above $60 \%$ of the heavy metals were removed in the microelectrolysis-Fenton oxidation section. Results above confirmed the effectiveness of $\mathrm{Fe} / \mathrm{C}$ microelectrolysis-Fenton oxidation for mature landfill leachate treatment in industrial application.
\end{abstract}

\section{Introduction}

The production of municipal solid wastes (MSW) has been increasing with the development of population. Presently, sanitary landfill is one of the most used methods for MSW disposal. The highly hazardous leachate produced from sanitary landfills is generally characterized by large amount of organic matter, ammonia nitrogen and various heavy metals [1-3]. The composition and biodegradability of landfill leachates are greatly depended on the age of the landfill[4]. Typically, the leachate of young landfills $(<1-2$ years age) have high biodegradability characteristics $\left(\mathrm{BOD}_{5} / \mathrm{COD}>0.5\right)$, but instead leachate in old-aged landfills (over 5 years age) have low biodegradability $\left(\mathrm{BOD}_{5} / \mathrm{COD}<0.1\right)$ and large fraction of refractory organics with high molecular weight $[5,6]$. Thereby, the biological processes commonly exhibit adequate ability for the treatment of young landfill leachate, while cannot satisfy the requirement for the removal of organic matter in mature leachates[6]. In this case, there has been increasing interest in physicochemical alternative treatment methods to improve the performance for mature landfill leachate treatment $[7$, 8].

Among the physicochemical treatments for biodegradability enhancement, advanced oxidation processes (AOPs) have been regarded as an efficient approach to recalcitrant organic matter decomposition $[9,10]$. Fenton oxidation as one of the AOPs has been extensively studied and used in mature landfill leachate treatment[11-13]. High reagent dosage of $\mathrm{H}_{2} \mathrm{O}_{2}$ and $\mathrm{Fe}^{2+}$ is required in Fenton oxidation process as to generate sufficient quantity of hydroxyl radicals, greatly raising the processing cost [14-16]. $\mathrm{Fe}-\mathrm{C}(\mathrm{Fe} / \mathrm{C})$ microelectrolysis was proposed as an efficient alternative for the production of $\mathrm{Fe}^{2+}$. Recent laboratory-scale studies found that $\mathrm{Fe} / \mathrm{C}$ microelectrolysis could both assisted the following treatment of Fenton oxidation without $\mathrm{Fe}^{2+}$ addition and $\mathrm{pH}$ adjustment, and also significantly enhanced the biodegradability of wastewater $[13,16-18]$. The two-stage advanced oxidation process of $\mathrm{Fe} / \mathrm{C}$ microelectrolysis and Fenton oxidation may be appropriate to industrial application $[8,16]$. Field investigations in mature landfill leachate treatment are the best way to validate the practical treatment efficiency for the two-stage advanced oxidation process [19]. However, there are few reports on the field-scale application of the two-stage advanced oxidation process for mature landfill leachate treatment.

\footnotetext{
*Corresponding author: ljm627@126.com
} 
The major objective of this study was to verify the field-scale performance of $\mathrm{Fe} / \mathrm{C}$ microelectrolysis-Fenton oxidation process on mature landfill leachate treatment. In the present study, leachate samples were collected from each treatment unit of a mature leachate treatment plant, in which the two-stage advanced oxidation process of $\mathrm{Fe} / \mathrm{C}$ microelectrolysis and Fenton oxidation coupled with the common biological degradation and coagulating sedimentation is applied for mature landfill leachate treatment. In order to systematically reveal the removal characteristics of the refractory pollutants in mature landfill leachate, this study analyzed the practical removal efficiency of refractory pollutants by each treatment through physicochemical characterization and the variation of the organic composition through spectral characterization. Meanwhile, the relevance between the removal of organics and other refractory pollutants (i.e. nitrogen and heavy metals) was investigated by correlation analysis.

\section{Materials and methods}

\subsection{Sample Collection}

Leachate samples were collected from the tanks at different treatment unit of a MSW landfill leachate treatment plant in Luoding city, Guangdong province, which has a daily waste-processing capacity of $48 \mathrm{t} / \mathrm{d}$. The entire treatment process of landfill leachate is illustrated in Figure 1. The treatment units include sedimentation basin (T1), biological denitrification tank (T2, $\Phi 6.0 \times 5.5 \mathrm{~m})$, tank of the $\mathrm{Fe} / \mathrm{C}$ microelectrolysis strengthened by $\mathrm{H}_{2} \mathrm{O}_{2} \quad$ (T3, $\Phi 0.87 \times 4.5 \mathrm{~m})$, Fenton oxidation tank $(\mathrm{T} 4)(1.84 \times 0.5 \times 0.8 \mathrm{~m})$, coagulative precipitation tank $(\mathrm{T} 5,3.2 \times 1.5 \times 4.2 \mathrm{~m})$, integrated activated sludge reactor (T6, $\Phi 4.5 \times 5.0 \mathrm{~m}$ ), filtration and sterilizing tank $(\mathrm{T} 7,1.0 \times 0.5 \times 1.0 \mathrm{~m})$. Among the 7 treatment tanks, struvite $\left(\mathrm{MgNH}_{4} \mathrm{PO}_{4} \cdot 6 \mathrm{H}_{2} \mathrm{O}\right)$ was used as $\mathrm{NH}_{3}-\mathrm{N}$ precipitant in T1 treatment, and polyacrylamide (PAM) was applied as the major coagulant in T5 treatment. T3 and T4 were the major constituents of the two-stage advanced oxidation process. About $25 \mathrm{~L}$ of the hydrogen peroxide solution ( $27.5 \%$, mass fraction) was diluted by 4 times with tap water and then pumped into $\mathrm{T} 3$ at $8.5 \mathrm{~L} / \mathrm{h}$. The influent $\mathrm{pH}$ of $\mathrm{T} 3$ was adjusted to 3 , and the hydraulic retention time in the T3 was about 1 hour. The effluent of T3 flowed into T4 to prolong the reaction time of Fenton oxidation, otherwise the unreacted $\mathrm{H}_{2} \mathrm{O}_{2}$ would adversely affect the following processes. Leachate samples collected from T1-T7 were centrifuged at $10,000 \mathrm{rpm}$ for $15 \mathrm{~min}$ and the liquid supernatant were stored in the dark at $4{ }^{\circ} \mathrm{C}$ before analysis. Some of the liquid supernatant was freeze-dried for FTIR analysis.

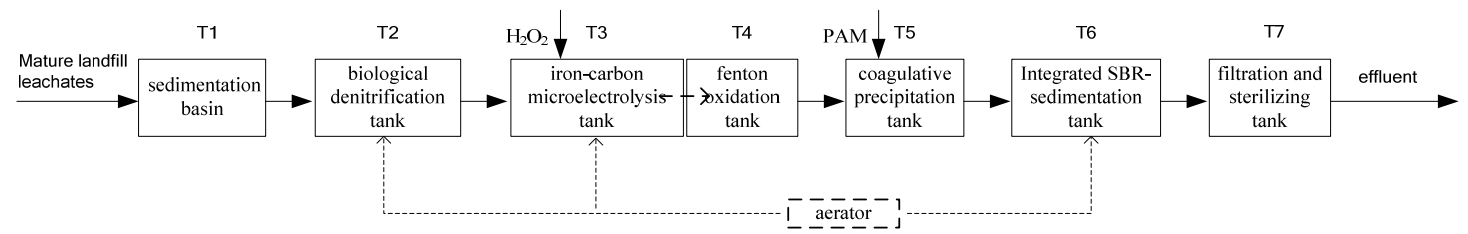

Figure 1 Diagram of the treatment process for MSW landfill leachates

\subsection{Elemental analysis}

$\mathrm{pH}$, ammonium nitrogen $\left(\mathrm{NH}_{4}{ }^{+}-\mathrm{N}\right)$, nitrate nitrogen $\left(\mathrm{NO}_{3}{ }^{-}-\mathrm{N}\right)$, nitrite nitrogen $\left(\mathrm{NO}_{2}^{-}-\mathrm{N}\right)$ and total nitrogen (TN) were measured according to the Standard Methods [20]. Dissolved organic carbon (DOC) was determined by DOC analyzer (DOC-VCPH, Shimadzu Corp., Japan). Heavy metals were determined by inductively coupled plasma mass spectroscopy (ICP-MS, ULTIMA, JY, France).

\subsection{Fluorescence spectra}

Synchronous fluorescence spectra and three-dimensional excitation and emission matrix (3D-EEM) fluorescence spectroscopy of the leachate were measured after filtration with a 0.45 um filter. Prior to fluorescence analysis, all leachate samples were diluted with ultrapure water to mitigate the inner-filtration effect caused by different DOC concentrations. The dilution ratio of $\mathrm{T} 1$ and $\mathrm{T} 2$ samples was 80:1 (v:v), and 10:1(v:v) for T3-T6 samples. Synchronous-scan excitation spectra were scanned from 260 to $500 \mathrm{~nm}$ with a constant offset of $30 \mathrm{~nm}$ using a Hitachi F-7000 model fluorescence spectrophotometer. Both the excitation and emission monochromators in the spectrophotometer had a slit width of $5 \mathrm{~nm}$, and the spectrophotometer operated at a scan speed of $500 \mathrm{~nm} / \mathrm{min}$. The 3D-EEM spectra of the samples were obtained by scanning emission wavelength from 200 to $500 \mathrm{~nm}$ and excitation wavelength from 200 to $450 \mathrm{~nm}$ at $5 \mathrm{~nm}$ intervals.

\subsection{UV-vis spectral analysis}

The UV-vis spectroscopy was obtained by scanning from 200 to $400 \mathrm{~nm}$. The absorbance at 254 and 280 $\mathrm{nm}$ was performed using a Shimadzu model UV-1700 PC spectrophotometer, and specific ultraviolet absorbance at $254 \mathrm{~nm}\left(\mathrm{SUVA}_{254}\right)$ and $280 \mathrm{~nm}\left(\mathrm{SUV}_{280}\right)$ were calculated by dividing the absorbance values at 254 and $280 \mathrm{~nm}$ by the corresponding DOC concentration, respectively. 


\subsection{FTIR spectral analysis}

The freeze-dried leachate samples were mixed with $\mathrm{KBr}$ (spec-trometry grade), and the mixtures were pressed under 10,000 $\mathrm{kPa}$ for $2 \mathrm{~min}$. FTIR spectra from the region between 4000 and $400 \mathrm{~cm}^{-1}$ were recorded on the $\mathrm{KBr}$ pellets using a Bruker model FTIR spec-trophotometer.

\section{Results and discussions}

\subsection{Basic physicochemical characteristics of the treated leachate}

The mature leachate received by the MSW landfill leachate treatment plant has an average landfill age of 7 years. The concentrations of $\mathrm{COD}, \mathrm{NH}_{3}-\mathrm{N}$ and $\mathrm{TN}$ in the mature leachate were within the range of 1590.9-1790.7 $\mathrm{mg} / \mathrm{L}, \quad 808.1-894.7 \mathrm{mg} / \mathrm{L}$ and
895.9-944.4 mg/L. The physicochemical characteristics of leachate from each processing section were shown in Table 1 . The leachate color was mainly removed by the biological denitrification process (T2) and the two-stage advanced oxidation (T3 and T4), accounting for $50 \%$ and $45 \%$ of the total color. The $\mathrm{NH}_{3}-\mathrm{N}$ in the leachate was effectively removed by biological denitrification process, significantly decreasing the concentration of $\mathrm{NH}_{3}-\mathrm{N}$ in leachate from 318.9 to 29.3 $\mathrm{mg} / \mathrm{L}$. The two-stage advanced oxidation coupled with coagulative precipitation (T5) exhibited high removal ability for heavy metals, decreasing the concentrations of $\mathrm{Pb}, \mathrm{Cd}, \mathrm{Ba}$ and $\mathrm{Cr}$ by $60 \%-100 \%$. Sludge enriched in $\mathrm{Fe}(\mathrm{OH})_{3}$ inevitablely generated during Fenton oxidation, and heavy metals in the leachate can transfer into the sludge by the flocculant precipitation of $\mathrm{Fe}(\mathrm{OH})_{3}$. The increase concentrations of $\mathrm{Fe}, \mathrm{Al}, \mathrm{Mn}$ and $\mathrm{Cr}$ in the effluent of $\mathrm{T} 3$ were likely contributed to the release of metals in the scrap cast iron during $\mathrm{Fe}-\mathrm{C}$ microelectrolysis process.

Table 1 Physicochemical characteristics of the effluents from each processing section

\begin{tabular}{ccccccc}
\hline $\mathrm{Samples}$ & $\mathrm{T} 1$ & $\mathrm{~T} 2$ & $\mathrm{~T} 3$ & $\mathrm{~T} 4$ & $\mathrm{~T} 5$ & $\mathrm{~T} 6$ \\
\hline $\mathrm{pH}$ & 7.56 & 7.47 & 2.51 & 2.55 & 8.9 & 7.8 \\
$\mathrm{Color}$ & 4000 & 2000 & 200 & 200 & 50 & 10 \\
$\mathrm{DO} /(\mathrm{mg} / \mathrm{L})$ & 2.52 & 13.22 & 14.77 & 18.12 & 14.83 & 14.45 \\
$\mathrm{ORP} /(\mathrm{mV})$ & -61 & -55 & 261 & 259 & -146 & -76 \\
$\mathrm{NH}_{3}-\mathrm{N} /(\mathrm{mg} / \mathrm{L})$ & 318.9 & 29.3 & 37.97 & 37.86 & 30.42 & 5.0 \\
$\mathrm{NO}_{2}-\mathrm{N} /(\mathrm{mg} / \mathrm{L})$ & 6.09 & 2.92 & 0 & 0 & 0.55 & 0 \\
$\mathrm{NO} \mathrm{O}_{3}-\mathrm{N} /(\mathrm{mg} / \mathrm{L})$ & 0.66 & 8.33 & 8.62 & 9.17 & 7.83 & 18.49 \\
$\mathrm{DON} /(\mathrm{mg} / \mathrm{L})$ & 86.5 & 50.1 & 13.6 & 13.54 & 19.35 & 0.95 \\
$\mathrm{TN} /(\mathrm{mg} / \mathrm{L})$ & 412.1 & 90.65 & 60.22 & 60.57 & 58.15 & 22.6 \\
$\mathrm{DOC} /(\mathrm{mg} / \mathrm{L})$ & 505.3 & 440.3 & 223.5 & 196.6 & 145.7 & 104.7 \\
$\mathrm{Cd} /(\mu \mathrm{g} / \mathrm{L})$ & 0.394 & 0.366 & 0.393 & 0.301 & 0.005 & 0.071 \\
$\mathrm{~Pb} /(\mu \mathrm{g} / \mathrm{L})$ & 3.42 & 2.05 & 1.53 & 1.44 & $\mathrm{ND}$ & 1.98 \\
$\mathrm{Cr} /(\mathrm{ug} / \mathrm{L})$ & 91.7 & 95.4 & 131 & 130 & 36.9 & 16.4 \\
$\mathrm{Fe} /(\mathrm{mg} / \mathrm{L})$ & 3.23 & 2.03 & 168 & 159 & 0.172 & 1.41 \\
$\mathrm{Al} /(\mathrm{mg} / \mathrm{L})$ & 0.338 & 0.122 & 4.3 & 4.08 & 0.103 & 0.248 \\
$\mathrm{Ca} /(\mathrm{mg} / \mathrm{L})$ & 160 & 149 & 158 & 150 & 13.7 & 29.7 \\
$\mathrm{Ba} /(\mathrm{ug} / \mathrm{L})$ & 298 & 170 & 83.2 & 87.3 & 2.03 & 24.7 \\
$\mathrm{Mn} /(\mathrm{ug} / \mathrm{L})$ & 1535 & 1302 & 2008 & 2062 & 3.46 & 252 \\
\hline
\end{tabular}

${ }^{a} \mathrm{ND}$, not detected

As shown in Table 1, DOC and DON were the major contaminants in the leachate after biological denitrification process (T2). The organics was largely removed by the following process of two-stage advanced oxidation, in which section the 
concentrations of DOC and DON were decreased by $58.30 \%$ and $79.28 \%$ compared to that in $\mathrm{T} 2$ effluent, respectively. About $95.09 \%$ of the residual DON after microelectrolysis-Fenton oxidation and coagulative precipitation was further removed by the activated sludge reactor (T6), while only $28.14 \%$ of the residual DOC was reduced by the T6 section. According to the previous laboratory studies, optimum results for organic matter (COD and DOC) removal by microelectrolysis-Fenton oxidation related processes were in the range of $58.5 \%-80 \%[14,16,18,21-25]$. In this field-scale study, the quantities of DOC and DON removed by the microelectrolysis-Fenton oxidation accounted for $48.17 \%$ and $42.27 \%$ of the total DOC and DON content in the raw landfill leachate, respectively. The lower removal ability of organics by the microelectrolysis-Fenton oxidation in field-scale than that in the laboratory scale was likely contributed to the unstable water quality of the raw leachate.

\subsection{Spectral analysis of the leachate from each processing section}

\subsubsection{Fluorescence spectra analysis}

The synchronous fluorescence spectra of the DOM in the leachate after T1-T6 treatment are shown in Figure 2. Following $\mathrm{T} 1$ and $\mathrm{T} 2$ treatment, two prominent peaks (A and B) could be identified from the leachate DOM. Peaks A and B centered at the wavelength of $285 \mathrm{~nm}$ and $340 \mathrm{~nm}$ were assigned to protein-like and fulvic-like fractions, respectively [26]. The fluorescent intensity per unit organic carbon (FI) of peak A was decreased to $73 \%$ by $\mathrm{T} 2$ treatment, instead no evident change was found for FI of peak B. Both the peaks almost disappeared in the leachate DOM after T2 and T3 treatment.

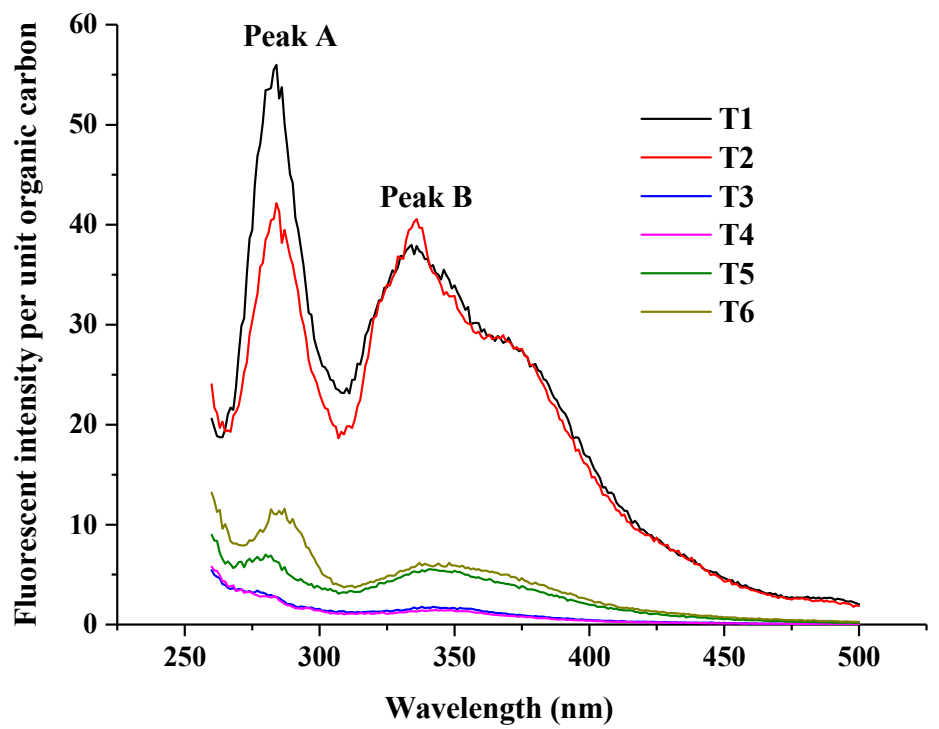

Figure 2 Synchronous-scan fluorescence spectra of the composting leachate DOM

The 3D-EEM spectra of leachate DOM after T1-T6 treatment are illustrated in Figure 3. Four fluorescence peaks (A, B, C and D) were observed in all the T1-T6 leachate DOM samples. According to the previous reports, peaks $\mathrm{A}$ and $\mathrm{B}$ were related to the tryptophan-like compounds[27, 28], while peaks $\mathrm{C}$ and $\mathrm{D}$ were respectively ascribed to $\mathrm{UV}$ and visible fulvic-like compounds[29, 30]. The principal peaks in the EEM spectra indicated that the leachate DOM was mainly composed of tryptophan-like and fulvic-like compounds, which is consistent with the results of synchronous fluorescence spectra. The detail results of the fluorescence peaks were summarized in Table 2 . The FI of peaks A and B after biological denitrification process (T2) was weakened by $26.8 \%$ and $25.6 \%$, respectively. In comparison, the FI of peaks C and D after biological denitrification process varied in a lesser degree. Therefore, compared to the tryptophan-like compounds, the fulvic-like compounds in the leachate DOM were much more difficult to be biodegraded by biological denitrification process. Following the two-stage advanced oxidation process (T3 and T4), the FI value of all the four peaks were dramatically reduced by $97.1 \%-98.3 \%$ and both the locations of peaks $\mathrm{B}$ and $\mathrm{C}$ were obviously blue-shifted, implying the decreases of molecular size and aromatic polycondensation. Such results suggested that the two-stage advanced oxidation process could efficiently decompose both tryptophan-like and fulvic-like compounds in the leachate DOM. The small increase of FI after T5 treatment may be contributed to the addition of PAM in coagulative precipitation process, which has the fluorescent functional groups (i.e. $-\mathrm{C}=\mathrm{O}$ and $-\mathrm{NH}_{2}$ ). 

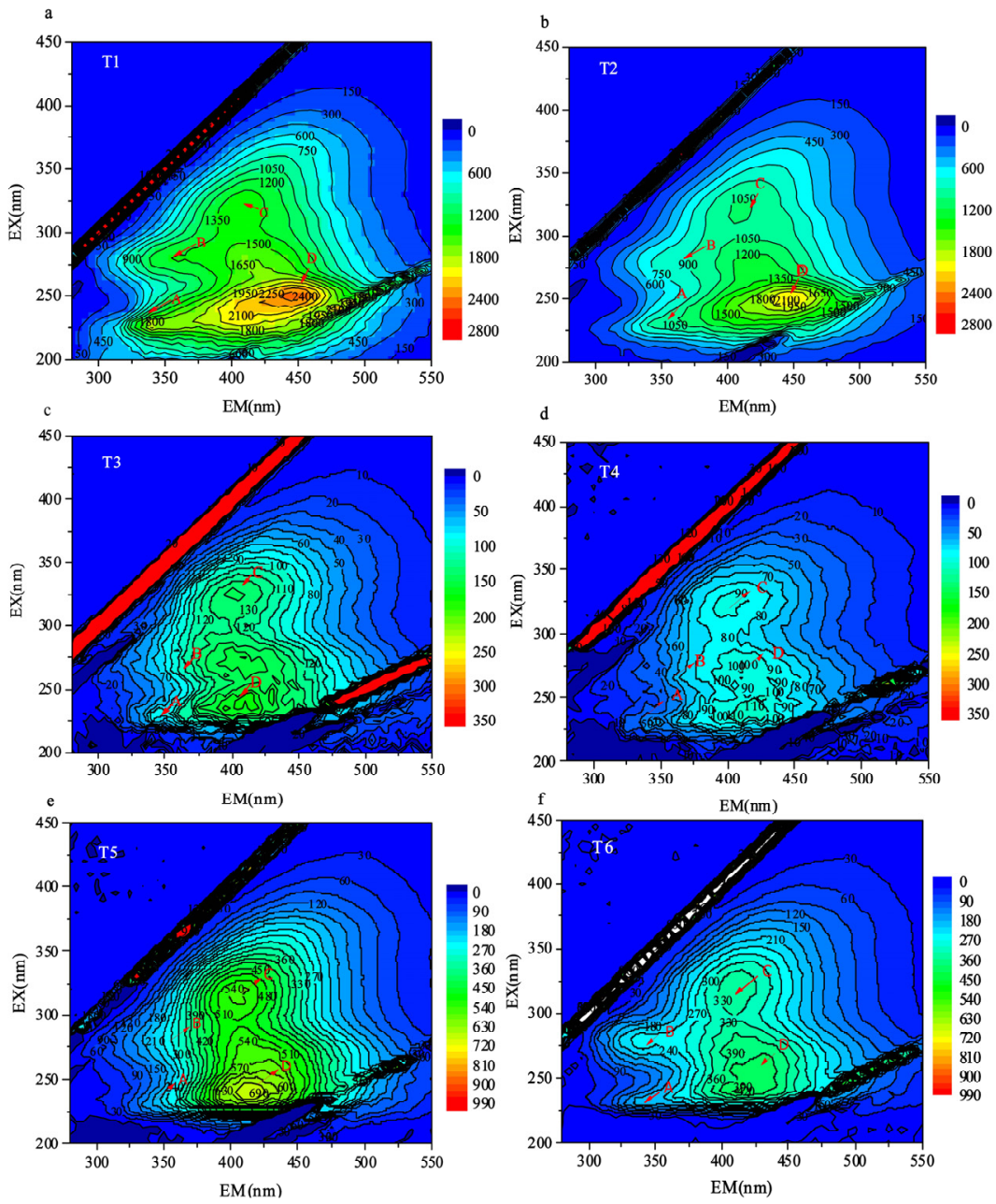

Figure 3 3D-EEM fluorescence spectroscopy of DOM in leachate samples

Table 2 The 3D-EEM fluorescence intensity of the leachate DOM in the effluents from each processing section

\begin{tabular}{|c|c|c|c|c|c|c|c|}
\hline \multicolumn{2}{|c|}{ Samples $^{\mathrm{a}}$} & $\mathrm{T} 1$ & $\mathrm{~T} 2$ & $\mathrm{~T} 3$ & $\mathrm{~T} 4$ & $\mathrm{~T} 5$ & T6 \\
\hline \multirow{3}{*}{ Peak A } & $\operatorname{Ex} / \operatorname{Em}(\mathrm{nm})$ & $228 / 340$ & $230 / 348$ & $226 / 342$ & $225 / 340$ & $230 / 339$ & $230 / 341$ \\
\hline & $\mathrm{TFI}^{\mathrm{b}}$ & 1886 & 1206 & 142.3 & 124.8 & 224 & 247 \\
\hline & $\mathrm{FI}^{\mathrm{c}}$ & 299 & 219 & 6.37 & 6.35 & 15.4 & 23.6 \\
\hline \multirow{3}{*}{ Peak B } & $\mathrm{Ex} / \mathrm{Em}(\mathrm{nm})$ & $280 / 360$ & $276 / 363$ & $275 / 356$ & $275 / 335$ & $278 / 336$ & $279 / 338$ \\
\hline & $\mathrm{TFI}^{\mathrm{b}}$ & 1408 & 911.7 & 137 & 82.6 & 231 & 305 \\
\hline & $\mathrm{FI}^{\mathrm{c}}$ & 223 & 166 & 6.13 & 4.20 & 15.9 & 29.1 \\
\hline \multirow{3}{*}{ Peak C } & $\mathrm{Ex} / \mathrm{Em}(\mathrm{nm})$ & $250 / 446$ & $250 / 445$ & $245 / 415$ & $245 / 420$ & $240 / 420$ & $240 / 412$ \\
\hline & $\mathrm{TFI}^{\mathrm{b}}$ & 2481 & 2138 & 178 & 127 & 707 & 441 \\
\hline & $\mathrm{FI}^{\mathrm{c}}$ & 393 & 388 & 7.96 & 6.46 & 48.5 & 42.1 \\
\hline \multirow{3}{*}{ Peak D } & $\operatorname{Ex} / \operatorname{Em}(\mathrm{nm})$ & $318 / 406$ & $322 / 412$ & $325 / 400$ & $324 / 400$ & $315 / 405$ & $317 / 410$ \\
\hline & TFI & 1456 & 1073 & 148.9 & 98.8 & 563 & 357 \\
\hline & FI & 231 & 195 & 6.66 & 5.03 & 38.6 & 34.1 \\
\hline
\end{tabular}

${ }^{a}$ The dilution ratio (DI) of T1 and T2 samples was 80:1 (v:v), and 10:1(v:v) for T3-T6 samples;

${ }^{\mathrm{b}}$ Total fluorescence intensity after dilution;

${ }^{c}$ Fluorescence intensity per unit organic carbon, $\mathrm{FI}=\mathrm{TFI} * \mathrm{DI} / \mathrm{DOC}$ 


\subsubsection{UV spectra analysis}

UV spectra of leachate DOM after T1-T4 treatment was presented in Figure 4. The two wavelength ranges of $200-220 \mathrm{~nm}$ and $240-400 \mathrm{~nm}$ could be mainly associated with the light absorption of compounds with ketonic $(\mathrm{C}=\mathrm{O})$ and aromatic $(\mathrm{C}=\mathrm{C})$ groups, respectively. With the proceeding of the treatment from $\mathrm{T} 1$ to $\mathrm{T} 4$, the absorbance increased gradually within the wavelength of 200-220 $\mathrm{nm}$ and instead decreased within the wavelength of 240-400 nm. This result suggested that aromatic compounds in leachate DOM could have been degraded into ketonic compounds during T1-T4 treatments. To further investigate the UV characteristics of the leachate DOM, specific UV absorbance determined at $254 \mathrm{~nm}\left(\mathrm{SUVA}_{254}\right)$ and 280 $\mathrm{nm}\left(\mathrm{SUV}_{280}\right)$ were measured. Table 3 shows the values $\mathrm{SUVA}_{254}$ and $\mathrm{SUV}_{280}$ of the leachates DOM after each treatment. The UV indicators of $\mathrm{SUVA}_{254}$ and $\mathrm{SUV}_{280}$ are both strongly correlated with the aromatic content in DOM [31, 32]. The values of SUVA 254 and SUV280 were respectively reduced from 0.0173 to 0.0052 and from 0.625 to 0.0935 by the two-stage advanced oxidation process, demonstrating that the combination of microelectrolysis and Fenton oxidation could efficiently decompose the aromatic compounds in the DOM of landfill leachate. Moreover, the lower values of $\mathrm{SUVA}_{254}$ and $\mathrm{SUV}_{280}$ were likely contributed to the subsequence coagulative precipitation treatment (T5).

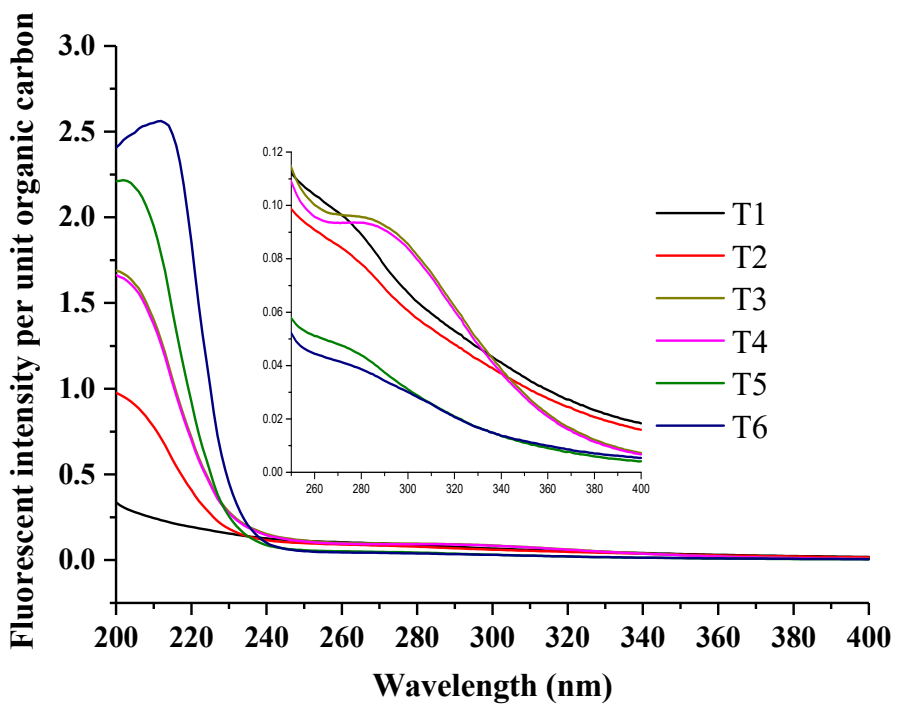

Figure 4 UV spectra of leachate DOM

Table 3 SUVA254 and SUV280 values of the leachates DOM after each treatment

\begin{tabular}{ccccccc}
\hline Samples & T1 & T2 & T3 & T4 & T5 & T6 \\
\hline SUVA $_{254}$ & 0.0171 & 0.0173 & 0.0048 & 0.0052 & 0.0037 & 0.0045 \\
SUV $_{280}$ & 0.714 & 0.625 & 0.0957 & 0.0935 & 0.0439 & 0.0387 \\
\hline
\end{tabular}

\subsubsection{FTIR spectra analysis}

Figure 5 demonstrated the FTIR spectra of the leachate DOM. As shown in Figure 5, the absorption bond at $1620-1640 \mathrm{~cm}^{-1}$ appeared in the effluents of T1 and T2 and began to disappear in the effluent of $\mathrm{T} 3$. Meanwhile, new absorption bond emerged at $1150-1200 \mathrm{~cm}^{-1}$ in the effluent of T3. The disappeared bond at $1620-1640 \mathrm{~cm}^{-1}$ after T3 treatment was associated with structural vibration of aromatic $\mathrm{C}=\mathrm{C}$, and the emerging band with increasing absorbance at $1150-1200 \mathrm{~cm}^{-1}$ was attributed to $\mathrm{C}-\mathrm{O}$ stretching and $\mathrm{O}-\mathrm{H}$ deformation of $\mathrm{COOH}$ [33]. Such variation of the two bonds indicated the transformation of the aromatic carbon into carboxylic acids in the $\mathrm{Fe} / \mathrm{C}$ microelectrolysis-Fenton oxidation section. The two bonds at $700 \mathrm{~cm}^{-1}$ and $840 \mathrm{~cm}^{-1}$ were attributed to the vibration of out-of-plane $\mathrm{NH}_{2}$ - in primary amine group and N-H wag in secondary amine group[34]. Both the two bonds only appeared in the effluents of T1-T2 and disappeared after T3 treatment, implying that DON likely exsisted in the form of amines and most amines have been decomposed by the $\mathrm{Fe} / \mathrm{C}$ microelectrolysis-Fenton oxidation. This result is consistent with the substantial decrease of DON content in the leachate DOM after T3 treatment (Table 1). The bond at $3400-3420 \mathrm{~cm}^{-1}$ was attributed to $\mathrm{O}-\mathrm{H}$ stretching in bond and non-bond hydroxyl group. The absorbance of this band exhibited a slight increase as treatment proceeded from $\mathrm{T} 1$ to $\mathrm{T} 4$, and exhibited an obvious decrease in T5 and T6 samples. The absorbance variation trend of the bond at 3400-3420 $\mathrm{cm}^{-1}$ resulted from the production of $\mathrm{O}-\mathrm{H}$ in the two-stage advanced oxidation process and the removal of $\mathrm{O}-\mathrm{H}$ containing compounds in coagulation sedimentation process. 


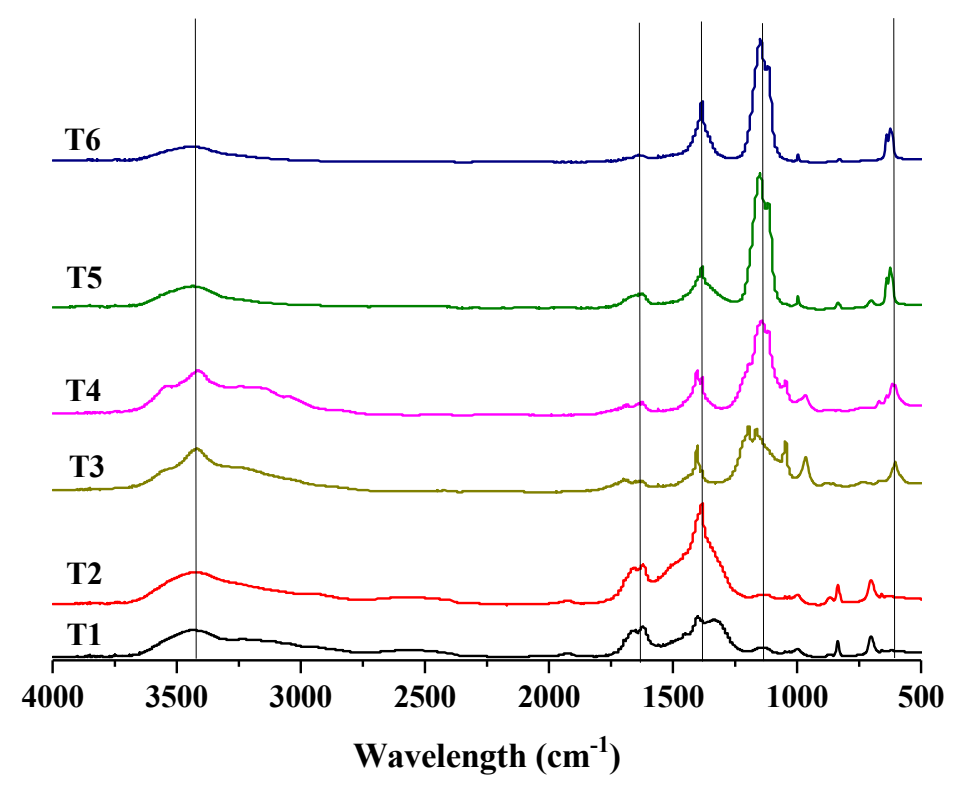

Figure 5 FTIR spectra of the composting leachate DOM

\subsection{Comprehensive analysis on the removal characterisitics of refractory pollutants}

Both UV and FITR spectra illustrated the presence of aromatic $\mathrm{C}=\mathrm{C}$ in the leachate before the microelectrolysis-Fenton oxidation, implying that aromatic $\mathrm{C}=\mathrm{C}$ may be the major constituent of DOC. According to the spectral analysis, microelectrolysis-Fenton oxidation process efficiently decomposed the aromatic $\mathrm{C}=\mathrm{C}$ into carboxyl- $\mathrm{C}$ and decreased the molecular size of the DOC. Correlation analysis was investigated to further reveal the relevance between the removal of DOC and other refractory pollutants (i.e. nitrogen and heavy metals). Table 4 shows the correlation coefficient between DOC, nitrogen and heavy metals in the leachate during T1-T6 treatment. As shown in Table 4, all the spectral indexes of $\mathrm{SUVA}_{254}, \mathrm{SUV}_{280}$ and FI positively and significantly associated with DON, indicating that organic nitrogen existed in the both aromatic and protein-like compounds. Besides, DON exhibited positive and significant correlation with $\mathrm{TN}(\mathrm{P}<0.01)$, but positive and significant correlation with $\mathrm{NO}_{3}-\mathrm{N}$ $(\mathrm{P}<0.01)$. Based on the results of FITR spectra results, most amine substances in leachate DOM have been decomposed by the microelectrolysis-Fenton oxidation. Thereby, it can be concluded from the results above that DON removal in the microelectrolysis-Fenton oxidation section may be closely associated with the $\mathrm{NH}_{2}$ - decomposition of tryptophan-like and aromatic compounds into $\mathrm{NO}_{3}-\mathrm{N}$.

The heavy metal of Ba positively and significantly $(\mathrm{P}<0.01)$ correlated with DOC and DON. Based on the analysis results from the fluorescence spectra, it could be deduced that a majority of the $\mathrm{Ba}$ in MSW landfill leachates were likely bound to the tryptophan-like compounds, which represent the bioavailable fraction of organic matter[35]. The concentrations of $\mathrm{Pb}$ and $\mathrm{Cd}$ were both positively associated with DOC, and DON, indicating that most $\mathrm{Pb}$ and $\mathrm{Cd}$ in MSW landfill leachates were likely bound to both the tryptophan-like and fulvic-like compounds. Consistent results that fulvic-like and protein-like fractions played important role in $\mathrm{Pb}$ and $\mathrm{Cd}$ binding have been reported by previous studies [21]. The concentration of $\mathrm{Cr}$ showed no obvious correlation to the DOC and DON fractions, suggesting that a small portion of $\mathrm{Cr}$ was bound to organic matter and most of them existed in the form of inorganic complexes or free ions.

Table 4 Correlation coefficients between organic matter, nitrogen and heavy metals

\begin{tabular}{cccccccccc}
\hline & $\mathrm{DON}$ & $\mathrm{NH}_{3}-\mathrm{N}$ & $\mathrm{NO}_{2}-\mathrm{N}$ & $\mathrm{NO}_{3}-\mathrm{N}$ & $\mathrm{TN}$ & $\mathrm{Cd}$ & $\mathrm{Pb}$ & $\mathrm{Cr}$ & $\mathrm{Ba}$ \\
\hline $\mathrm{SUVA}_{254}$ & $0.903^{*}$ & 0.626 & $0.898^{*}$ & 0.585 & 0.703 & 0.609 & 0.734 & 0.217 & $0.892^{*}$ \\
$\mathrm{SUV}_{280}$ & $0.944^{* *}$ & 0.704 & $0.937^{* *}$ & 0.657 & 0.774 & 0.622 & 0.785 & 0.234 & $0.927^{* *}$ \\
$\mathrm{FI}($ peak A) & $0.959^{* *}$ & 0.765 & $0.972^{* *}$ & 0.638 & $0.828^{*}$ & 0.525 & 0.870 & 0.108 & $0.920^{* *}$ \\
$\mathrm{FI}($ peak B) & $0.949^{* *}$ & 0.755 & $0.967^{* *}$ & 0.608 & $0.818^{*}$ & 0.499 & 0.876 & 0.069 & $0.907^{*}$ \\
$\mathrm{FI}($ peak C) & $0.910^{*}$ & 0.631 & $0.915^{*}$ & 0.571 & 0.709 & 0.486 & 0.770 & 0.075 & $0.849^{*}$ \\
\hline
\end{tabular}




\begin{tabular}{cccccccccc}
\hline FI(peak D) & $0.936^{* *}$ & 0.701 & $0.949^{* *}$ & 0.596 & 0.771 & 0.448 & 0.838 & 0.027 & $0.864^{*}$ \\
DOC & $0.948^{* *}$ & 0.727 & $0.919^{* *}$ & 0.749 & 0.790 & 0.729 & 0.737 & 0.390 & $0.951^{* *}$ \\
DON & 1.000 & $0.871^{*}$ & $0.988^{* *}$ & $-0.820^{*}$ & $0.918^{* *}$ & 0.547 & 0.874 & 0.211 & $0.938^{* *}$ \\
\hline
\end{tabular}

*Correlation is significant at the 0.05 level (two-tailed).

**Correlation is significant at the 0.01 level (two-tailed).

\section{Conclusions}

This paper investigated the field-scale performance of $\mathrm{Fe}-\mathrm{C}$ microelectrolysis-Fenton oxidation process combined with biological degradation and coagulative precipitation for mature landfill leachate treatment. The organic matter was mainly removed by $\mathrm{Fe}-\mathrm{C}$ microelectrolysis-Fenton oxidation process, decreasing the concentrations of DOC and DON by $48.17 \%$ and $42.27 \%$, respectively. Spectral analysis further demonstrated that aromatic $\mathrm{C}=\mathrm{C}$ may be the major constituent of DOC, and microelectrolysis-Fenton oxidation process efficiently decomposed the aromatic $\mathrm{C}=\mathrm{C}$ into carboxyl- $\mathrm{C}$ and decreased the molecular size of the DOC, reducing the fluorescence intensity of tryptophan-like and fulvic-like compounds by $97.1 \%-98.3 \%$. The DON removal by microelectrolysis-Fenton oxidation likely associated with the $\mathrm{NH}_{2}$ - decomposition of tryptophan-like and aromatic compounds into $\mathrm{NO}_{3}-\mathrm{N}$. The final concentrations of DOC and DON were reduced to $104.7 \mathrm{mg} / \mathrm{L}$ and $0.95 \mathrm{mg} / \mathrm{L}$ by the following activated sludge reactor, respectively. Additionally, above $60 \%$ of the heavy metals $(\mathrm{Pb}, \mathrm{Cd}, \mathrm{Ba}$ and $\mathrm{Cr}$ ) were removed by the microelectrolysis-Fenton oxidation section coupled with coagulative precipitation.

\section{Acknowledgments}

This work was financially supported by Beijing Natural Science Foundation (8182057) and Primary Research \& Developement Plan of Hunan Province (2018SK2023).

\section{References}

[1] P. Kjeldsen, M.A. Barlaz, A.P. Rooker, A. Baun, A. Ledin, T.H. Christensen, Critical Reviews in Environmental Science and Technology, 32 (2002) 297-336.

[2] T. Y, Environmental technology, 9 (2003) 1135-1145.

[3] Z. Yuan, C. He, Q. Shi, C. Xu, Z. Li, C. Wang, H. Zhao, J. Ni, Environmental Science \& Technology, 51 (2017) 8110-8118.

[4] S. Baig, I. Coulomb, P. Courant, P. Liechti, Science \& Engineering, 21 (1999) 1-22.

[5] L. Antonio, Chemosphere, 7 (2004) 1005-1010.

[6] T.A. Kurniawan, W.H. Lo, G.Y. Chan, Journal of hazardous materials, 129 (2006) 80-100.
[7] P. Travanca, J. Jesus, J. Tomaos Veiga Soares De Albergaria, M.T. Oliva-Teles, C. Maria Fernandes Delerue Alvim De Matos, A. S. Danko, International Journal of Hydrology Science and Technology, 7 (2017) 158.

[8] A. Baiju, R. Gandhimathi, S.T. Ramesh, P.V. Nidheesh, Journal of environmental management, 210 (2018) 328-337.

[9] Y. Deng, International Journal of Environment and Waste Management,4 (2009) 366-384.

[10]R. Nousheen, A. Batool, M. Saif Ur Rehman, M. Asad Ghufran, T. Hayat, T. Mahmood, Journal of the Taiwan Institute of Chemical Engineers, 45 (2014) 1661-1665.

[11]E. Kattel, M. Trapido, N. Dulova, The Chemical Engineering Journal, 304 (2016) 646-654.

[12]T. Sruthi, R. Gandhimathi, S.T. Ramesh, P.V. Nidheesh, Chemosphere, 210 (2018) 38-43.

[13] K. Luo, Y. Pang, X. Li, F. Chen, X. Liao, M. Lei, Y. Song, Environmental Technology, 40 (2019) 1862-1870.

[14]U. Muhammad, Waste management (New York, N.Y.), 30 (2010) 2113-2121.

[15] J. Xu, Y. Long, D. Shen, H. Feng, T. Chen, Journal of hazardous materials, 323 (2017) 674-680.

[16]L. Wang, Q. Yang, D. Wang, X. Li, G. Zeng, Z. Li, Y. Deng, J. Liu, K. Yi, Journal of hazardous materials, 318 (2016) 460-467.

[17]X. Xu, Y. Cheng, T. Zhang, F. Ji, X. Xu, Chemosphere, 152 (2016) 23-30.

[18]H. Zhang, L. Xiang, D. Zhang, H. Qing, Desalination and Water Treatment, 47 (2012) 243-248.

[19]A.G. van Turnhout, C. Brandstatter, R. Kleerebezem, J. Fellner, T.J. Heimovaara, Waste management (New York, N.Y.), 71 (2018) 246-254.

[20] W. G. Walter, American Journal of Public Health and the Nations Health, 51 (1961) 940.

[21] W. Jun, Water research, 45 (2011) 1711-1719.

[22]D. Ying, J. Peng, X. Xu, K. Li, Y. Wang, J. Jia, Journal of hazardous materials, 229-230 (2012) 426-433.

[23]A. Talebi, N. Ismail, T.T. Teng, A. Alkarkhi, Desalination \& Water Treatment, 52 (2014) 1524-1530. 
[24] L. Zhao, X. Gu Cheng, P. He Yin, G. Lu, J. Chang Suo, Applied Mechanics and Materials, 448-453 (2013) 1399-1402.

[25]Z. Yang An, X. Jun Xu, Advanced Materials Research, 573-574 (2012) 492-496.

[26]C. Wei, Environmental science \& technology, 49 (2015) 2052-2058.

[27]C. Wen, Environmental science \& technology, 37 (2003) 5701-5710.

[28] C. Stedmon, R. Cory, (2014).

[29]A. Baker, M. Curry, Water research, 38 (2004) 2605-2613.
[30]Z. Zhong, Water research, 41 (2007) 4696-4702

[31] C. Y P, Environmental science \& technology, 28 (1994) 1853-1858.

[32] N. Wataru, Chemosphere, 56 (2004) 113-119.

[33]A. Piccolo, F.J. Stevenson, Geoderma, 27 (1982) 195-208.

[34] S. Ena, Waste management (New York, N.Y.), 27 (2007) 268-276.

[35]H. Naomi, The Science of the total environment, 391 (2008) 149-158 